\title{
The impact of "COVID-mania" on medical scientific literature. Are we facing a publication pandemic?
}

\author{
Maria Sotiropoulou - Dimitrios Schizas · Francesk Mulita - loannis Maroulis - Michail Vailas (D)
}

Received: 11 March 2021 / Accepted: 27 March 2021 / Published online: 6 May 2021

(c) Springer-Verlag GmbH Austria, part of Springer Nature 2021

\section{Dear Editor,}

We have lately read articles published in the scientific literature regarding the impact of COVID-19 (coronavirus disease of 2019) on undergraduate and residency training, and we agree with the modifications and remodulation of the teaching modalities that are currently followed in order to maintain high standards of medical education during the pandemic [1]. However, we strongly believe that access to scientific literature and medical research is, along with other modalities, an indispensable part of the training of new doctors and surgeons. Many researchers have lately questioned the quality of recently published articles regarding the new pandemic (Fig. 1). Is there a true and justified danger underling this criticism?

A novel coronavirus was discovered in December 2019 in Wuhan, China, and became a pandemic soon after, with over 98 million reported cases and 2 million deaths [2]. The COVID-19 pandemic is having a major impact not only on public health, but also on scientific literature, with over 92,000 articles published in PubMed under the term "COVID-19"; an unprecedented situation that puts in question the quality of these data in such a short time period. Undoubtedly, COVID-19 has significantly changed the way medical education continues to be carried out among health
M. Sotiropoulou, MD · D. Schizas, MD, PhD .

M. Vailas, MD $(\bowtie)$

First Department of Surgery, National and Kapodistrian University of Athens, Laikon General Hospital, 17 Agiou Thoma, 11527 Athens, Greece mike_vailas@yahoo.com

F. Mulita, MD · I. Maroulis, MD, PhD Department of Surgery, University of Patras, University Hospital of Patras, 26504 Patra, Greece care workers, with scientific writing still being a cornerstone of continuous medical education [3, 4].

Apart from the studies associated with virologic and basic scientific information about the novel coronavirus, there is a plethora of studies reporting possible implications of the virus for patient management and the risk of infection, while there is scarcity of papers reporting findings from RCTs on drugs and treatments; only one clinical trial was conducted on human subjects [5,6]. Researchers and readers feel stunned by the numbers of papers reporting associations of the novel coronavirus with several medical conditions. Is this a new "discovery of the wheel" or a surge in scientific data with no meaningful impact?

It is true that most of the aforementioned studies are mostly opinion articles by authors who put out ideas and share organizational experience, with few original studies published [7]. Strikingly enough, the number of "opinion" articles is $>3$ times the number
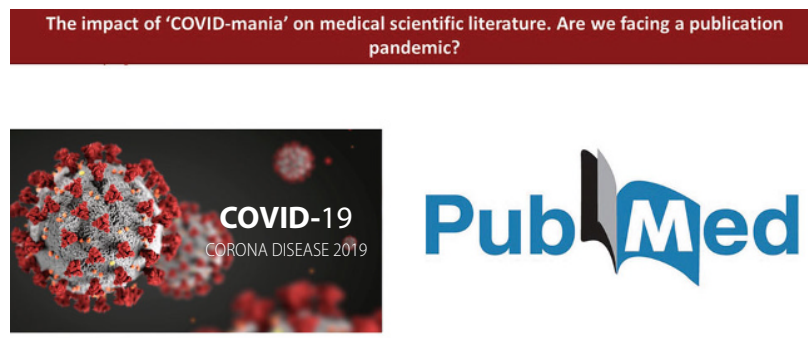

Fig. 1 COVID-19 and scientific literature. (COVID-19: (C) Mauro Rodrigues/stock.adobe.com; PubMed-Logo: Wikimedia Commons contributors, "File:US-NLM-PubMedLogo.svg," Wikimedia Commons, https://commons. wikimedia. org/w/index.php?title=File:US-NLM-PubMed-Logo.svg\& oldid $=555296493$ [accessed April 27th, 2021].) 


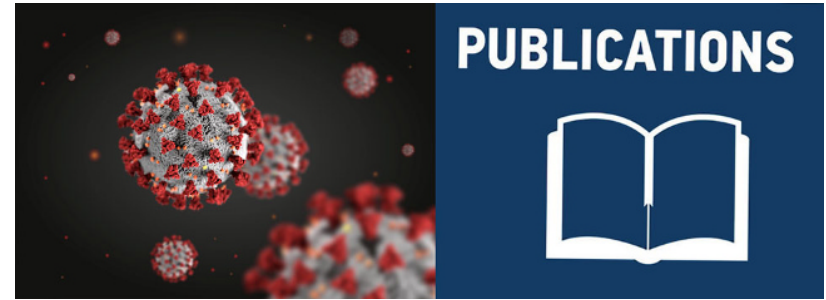

Fig. 2 Publications during the pandemic. (COVID-19: (C) Mauro Rodrigues/stock.adobe.com)

of original investigations published during this period [8]. Nonetheless, neither the authors nor the editors should be criticized regarding this situation. There are serious concerns regarding the large bulk of articles already published, which could be misleading for readers and physicians, due to their questionable methodology in many cases (Fig. 2).

Numerous journals prioritize COVID-19-related scientific writing, giving researchers the chance of quicker public access to peer-reviewed articles. While this phenomenon is encouraging for further elucidation of the riddle of this novel coronavirus, this acceleration of the peer-review process may reflect a change in publication standards from journals in a way which may compromise the integrity of research [6]. Many writers have lately raised concerns about whether there is nowadays a proportion of researchers who use COVID-19 as a "Trojan horse" in order to easily enter the world of science and augment their impact. Even our article may seem of ironic nature and could be interpreted as an opportunistic effort to gain another publication.

It is of great importance for clinicians to carefully evaluate the existing scientific data regarding this pandemic, be able to interpret thoroughly their results, and also avoid possible generalizations on COVID and various diseases, with no meaningful justification. In the setting of a major health crisis like the pandemic we are now facing, there is a great need and expectation for the medical community to publish high-quality papers. The uncertainty characterizing the new groundbreaking situation which affects humanity in our times has inevitably influenced all aspects of our lives, including medical literature. Hopefully, after the de-escalation of this situation, scientists will be able to fully appreciate the extreme load of medical literature published during this era.

\section{What is new?}

- The SARS-CoV-2 pandemic has unprecedented eff ects in every aspect of our lives.

- There is an extremely large bulk of scientific articles related to the new coronavirus already published, a fact that raises concerns about the validity of the studies' methodology.

- After the de-escalation of this situation, future studies will be needed in order to appreciate this extreme load of medical literature during this era.

Author Contribution M. Sotiropoulou, D. Schizas, F. Mulita, I. Maroulis and M. Vailas made substantial contributions to the conception, design and writing of the work, M. Vailas supervised this research project.

Conflict of interest M. Sotiropoulou, D. Schizas, F. Mulita, I. Maroulis and M. Vailas declare that they have no conflict of interest.

Funding statement This research received no specific grant from any funding agency in the public, commercial, or notfor-profit sectors.

\section{References}

1. Giordano L, Cipollaro L, Migliorini F, Maffulli N. Impact of Covid-19 on undergraduate and residency training. Surgeon. 2020;12:S1479-666X(20)30169-4.

2. Guan WJ, Ni ZY, Hu Y, Liang WH, Ou CQ, He JX, et al. Clinical Characteristics of Coronavirus Disease 2019 in China. NEngl J Med. 2020;382(18):1708-20.

3. Stanton B. Medical education in the age of COVID19. Acad Med. 2020. https://doi.org/10.1097/ACM. 0000000000003890.

4. Khan S, Mian A. Medical education: COVID-19 and surgery. BrJSurg. 2020;107(8):e269.

5. Picciariello A, Gagliardi G, Altomare DF. It's COVID o'clock. BrJSurg. 2020;107(11):e520.

6. Liu N, Chee ML, Niu C, Pek PP, Siddiqui FJ, Ansah JP, et al. Coronavirus disease 2019 (COVID-19): an evidence map of medical literature. Bmc Med Res Methodol. 2020;20(1):177.

7. Bauchner H, Fontanarosa PB, Golub RM. Editorial evaluation and peer review during a pandemic: how journals maintain standards. JAMA. 2020;324(5):453-4.

8. Elgendy AY, Barakat AF, Ibrahim J, Alkukhun L, Mamas MA, ElgendyIY.TheLandscape of MedicalLiteraturein theEra of COVID-19: Original Research Versus Opinion Pieces. J Gen Intern Med. 2020;35(9):2813-5.

Publisher's Note Springer Nature remains neutral with regard to jurisdictional claims in published maps and institutional affiliations. 